\title{
Extraction and purification of oridonin from Rabdosia rubescens and its protective effect on intracerebral hemorrhage-induced brain injury in rats
}

\author{
Tie $\mathrm{LI}^{1 \#}$, Xueyan WANG ${ }^{1 \#}$, Kun DONG ${ }^{1 \star}$
}

\begin{abstract}
Oridonin was extracted and purified from Rabdosia rubescens and its protective effect on intracerebral hemorrhage (ICH)induced brain injury in rats was investigated. The rats were divided into sham, model, low-dose oridonin, middle-dose oridonin and high-dose oridonin groups. The ICH-induced brain injury model was established in latter four groups. After modeling, the low-, middle- and high-dose oridonin groups were treated with 10,20 , and $40 \mathrm{mg} / \mathrm{kg}$ oridonin at $2 \mathrm{~h}$ and $24 \mathrm{~h}$ after modeling, respectively. Results showed that, after 48 after modeling, compared with model group, in middle- and high-dose oridonin groups the modified Neurological Severity Score was significantly decreased $(\mathrm{P}<0.05)$, the brain water content was significantly decreased $(\mathrm{P}<0.05)$, the brain tissue tumor necrosis factor $\alpha$, interleukin $1 \beta$, interleukin 6 and nuclear factor-kappa B $(\mathrm{NF}-\kappa \mathrm{B})$ p65 protein levels were significantly decreased $(\mathrm{P}<0.05)$, and the brain tissue erythroid 2-related factor $2(\mathrm{Nrf2})$ and heme oxygenase $1(\mathrm{HO}-1)$ protein levels were significantly increased $(\mathrm{P}<0.05)$. In conclusion, oridonin from Rabdosia rubescens can mitigate the ICH-induced brain injury in rats. The mechanism may be related to its reduction of inflammatory response and oxidative stress by inhibiting NF- $\mathrm{\kappa B}$ inflammatory pathway and promoting Nrf2/HO-1 antioxidant pathway in brain tissues.
\end{abstract}

Keywords: oridonin; intracerebral hemorrhage; NF-кB; Nrf2; HO-1.

Practical Application: This study has provided a reference for preparation of oridonin from Rabdosia rubescens and application of it to treat intracerebral hemorrhage-induced brain injury.

\section{Introduction}

Intracerebral hemorrhage $(\mathrm{ICH})$ is one of the acute cerebrovascular diseases, which accounts for $10 \%$ to $20 \%$ of all strokes worldwide and is associated with high morbidity and mortality (Rindler et al., 2020). The pathophysiological mechanism of ICH is complex. The secondary brain injury caused by ICH is an important factor leading to the neurological damage (Belur et al., 2013). More and more studies have shown that the inflammatory response and oxidative stress after hematoma formation are closely related to the ICH-induced brain injury and neurological dysfunction (Wasserman et al., 2007; Sugiyama et al., 2018). At present, the clinical treatment of ICH-induced brain injury includes supportive measures and surgery (Thiex and Tsirka, 2007; Holste et al., 2021). It is very important to find effective drugs to prevent and treat $\mathrm{ICH}$ induced brain injury and the neurological dysfunction. Rabdosia rubescens belongs to the Lamiaceae plants. Modern research has proved that Rabdosia rubescens has the heat-clearing, antitumor, blood circulation-promoting and pain-relieving functions (Sartippour et al., 2005). Oridonin, a diterpenoid compound, is the main active component of Rabdosia rubescens. Oridonin has many biological effects in anti-inflammatory, antibacterial, anti-tumor, antioxidant and other aspects (Xu et al., 2009; Li et al., 2016; Zheng et al., 2016). It is found that, the nuclear factor-kappa B (NF- $\mathrm{KB}$ ) inflammatory pathway (Zhang et al., 2015) and nuclear factor erythroid 2-related factor $2 /$ heme oxygenase 1
(Nrf2/HO-1) antioxidant pathway (Wei et al., 2017) are involved in the ICH-induced brain injury. The role and mechanism of oridonin in ICH-induced brain injury are still unclear. In this study, oridonin was extracted and purified from Rabdosia rubescens. The protective effect of oridonin on ICH-induced brain injury in rats was investigated, and the mechanism related to NF- $\mathrm{KB}$ inflammatory pathway and Nrf2/HO-1 antioxidant pathway. The objective was to lay a theoretical basis for further studying the effect of oridonin for ICH-induced brain injury.

\section{Materials and methods}

\subsection{Extraction and purification of oridonin from Rabdosia rubescens}

A $500 \mathrm{~g}$ of dry Rabdosia rubescen powder was placed in the ultrasonic extractor, followed by extraction with $5 \mathrm{~L}$ of $95 \%$ ethanol-water solution for two times. The extracted solution of two times was combined, and was concentrated to $1 / 3$ of original volume. The activated carbon was added to the concentrated solution. The decolorization under ultrasonic condition was performed for $30 \mathrm{~min}$. After filtering under reduced pressure, the decolorized extracted solution was obtained. After further concentrating, the crude extract was obtained. The silica gel 5 times mass of crude extract was packed into the chromatographic 
column, and then the crude extract was loaded on the column. The eluention was performed using petroleum ether-acetone solution (6:4) as eluent. Using oridonin standard as reference substance, the thin layer chromatography method was used for tracking the oridonin in elution solution. The target elution solution was collected and concentrated to appropriate volume, followed by placing at $4{ }^{\circ} \mathrm{C}$ for 2 days, and the crystals precipitated. After filtering under reduced pressure, the crystals were obtained. After washing with a small amount of acetone to white, the crystals were dried, and the final oridonin product with HPLC purity of $97.42 \%$ was obtained.

\subsection{Establishment of ICH-induced brain injury model}

The SD rats (220-500 g) were used for establishment of ICH-induced brain injury model. After anesthesia, the rats were fixed on the brain stereopositioning instrument. After the hair removing and skin sterilizing, the anterior fontanelle was fully exposed by sagittally incising at midbrain. A hole with about $1 \mathrm{~mm}$ diameter was made using dental drill at the position $3.5 \mathrm{~mm}$ right and $0.2 \mathrm{~mm}$ before the anterior fontanelle. A $100 \mu \mathrm{L}$ of autogenous blood was taken from right femoral artery using the micro syringe. Then, the micro syringe was vertically inserted (5.5 $\mathrm{mm}$ depth) into the hole, and the autogenous blood was completely injected. The wound was sutured, and the rats were placed to the cage. In sham-operated rats, only the micro syringe was inserted, without autogenous blood injection.

\subsection{Grouping of rats and treatment}

Sixty successfully modeled rats were randomly divided into four groups: model group, low-dose oridonin group, middle-dose oridonin group and high-dose oridonin group, 15 rats in each group. In addition, 15 sham-operated rats were selected as the sham group. At $2 \mathrm{~h}$ after modeling, the rats in low-, middle- and highdose oridonin groups were given 10,20 , and $40 \mathrm{mg} / \mathrm{kg}$ oridonin by intraperitoneal injection, respectively. The treatment was performed again at 24 after modeling, respectively. The rats in sham and model groups were synchronously given the same amount of normal saline. All rats were raised under the conditions that met the requirements of environmental facilities for medical laboratory animals.

\subsection{Neurobehavioral test}

After 48 after modeling, the neurobehavioral test was performed in each group. The neurological function of rats was evaluated using the modified Neurological Severity Score (mNSS) system. The items included the motor, sensory, balance, and reflex tests. The scores from all the tests were summed to give the $0-18$ points. The mild, moderate and severe neurological dysfunction were described as a score of 1-6 points, 7-12 points and 13-18 points, respectively (Hong et al., 2020). Rats were tested by an experimenter who was blind to the group identity of the animal three times, and the average was recorded.

\subsection{Determination of brain water content}

After neurobehavioral test, six rats in each group were taken. After anesthesia, the rats were killed. The skull was opened, and the brains were taken. The olfactory brain, cerebellum and low brain stem were removed. The remaining brain tissues were weighed to obtain the wet brain mass. Then, the brain tissues were placed in the oven at $105-115^{\circ} \mathrm{C}$ to constant weight to obtain the dry brain mass. The brain water content was calculated as follows: brain water content $(\%)=[$ (wet brain mass - dry brain mass) / wet brain mass] $\times 100 \%$.

\subsection{Determination of inflammatory factor levels in brain tissues}

The remaining rats in each group were taken. The partial brain tissues were taken, and weighed. After grinding with normal saline, the brain homogenate was prepared. and rinsed with normal saline. After centrifuging at $3000 \mathrm{r} / \mathrm{min}$ for $10 \mathrm{~min}$, the supernatant was obtained. The tumor necrosis factor $\alpha$ (TNF- $\alpha$ ), interleukin $1 \beta$ (IL-1 $\beta$ ) and interleukin 6 (IL-6) levels were detected by enzyme linked immunosorbent assay. The procedures followed the instructions of kits.

\subsection{Determination of NF- $\kappa B$ p65, Nrf2 and HO-1 protein expression levels in brain tissues}

Partial brain tissues were taken, and weighed. After rinsing with normal saline, about $100 \mathrm{mg}$ of brain tissues were taken, and was homogenized. The protein was extracted. The NF- $\kappa B$ p 65 , Nrf2 and HO-1 protein expression levels were determined using western blot assays. $\beta$-actin was used as the internal reference. The relative expression level of target protein was expressed by the ratio of its integral optical density to that of $\beta$-actin. The procedures were in accordance to the instructions of kits.

\subsection{Statistical analysis}

Data were presented as mean \pm standard deviation. The statistical analysis was performed using SPSS 18.0 software (SPSS Inc., Chicago, USA). The difference among different groups was analyzed using one-way analysis of variance with SNK-q test for individual comparisons between group means. $\mathrm{P}<0.05$ indicated statistically significant.

\section{Results}

\subsection{Behavioral manifestations and survival of rats in five groups}

During $48 \mathrm{~h}$ of observation period after modeling, in sham group the rats had basically normal behavioral activities, with glossy hair and no loose stool. The rats in model group showed emotional instability, timidity, persistent high alertness and hair irregularity. The behavioral manifestations in three treatment groups were similar with those in model group, but the degree was obviously decreased, especially in high-dose oridonin group. At the end, there were $0,4,3,1$ and 1 rats which died in sham, model, low-dose oridonin, middle-dose oridonin and highdose oridonin groups, respectively, with survival rate of $100 \%$, $73.33 \%, 80.00 \%, 93.33 \%$ and $93.33 \%$, respectively.

\subsection{Comparison of mNSS among five groups}

At $48 \mathrm{~h}$ after modeling, the mNSS in sham, model, lowdose oridonin, middle-dose oridonin and high-dose oridonin groups was $0.72 \pm 0.12,9.88 \pm 1.78,8.95 \pm 1.34,7.51 \pm 1.23$ and 
$6.47 \pm 0.90$ points, respectively. Compared with sham group, the mNSS in model group and three oridonin treatment groups was significantly increased, respectively $(\mathrm{p}<0.05)$. Compared with model group, the mNSS in middle-dose and high-dose oridonin groups was significantly decreased, respectively $(\mathrm{P}<0.05)$ (Figure 1).

\subsection{Comparison of brain water content among five groups}

As shown in Figure 2, brain water content in sham, model, low-dose oridonin, middle-dose oridonin and high-dose oridonin groups was $(77.64 \pm 0.32) \%$, $(79.47 \pm 0.56) \%$, $(79.12 \pm 0.30) \%$, $(78.56 \pm 0.28) \%$ and $(78.13 \pm 0.12) \%$, respectively. Compared with sham group, the brain water content in other four groups was significantly increased, respectively $(\mathrm{p}<0.05)$. Compared with model group, the brain water content in middle-dose and high-dose oridonin groups was significantly decreased, respectively $(\mathrm{P}<0.05)$.

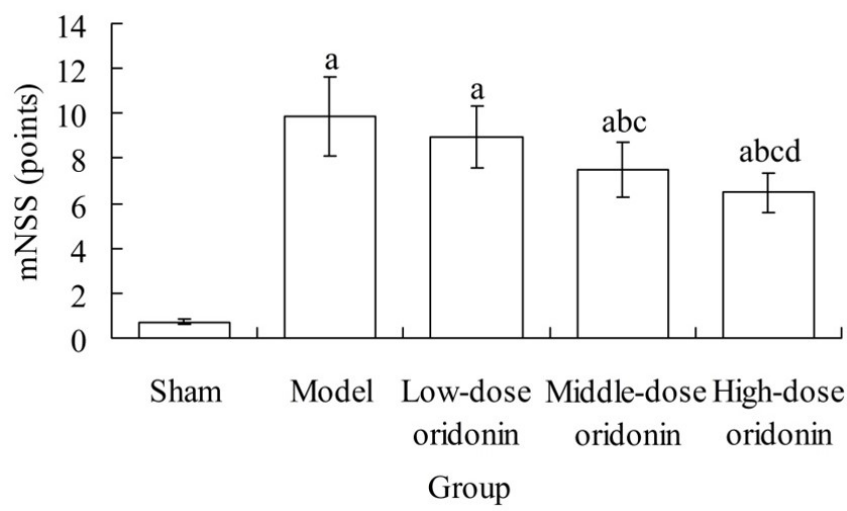

Figure 1. Comparison of mNSS among five groups (sham group: $\mathrm{n}=15$; model group: $\mathrm{n}=11$; low-dose oridonin group: $\mathrm{n}=12$; middle-dose oridonin group: $\mathrm{n}=14$; high-dose oridonin group: $\mathrm{n}=14 ; \mathrm{F}=132.775$; $\mathrm{P}<0.001)$. ${ }^{\text {aP }}<0.05$ compared with sham group; ${ }^{\text {b }}<0.05$ compared with model group; ${ }^{\mathrm{c}} \mathrm{P}<0.05$ compared with low-dose oridonin group; ${ }^{\mathrm{d}} \mathrm{P}<0.05$ compared with middle-dose oridonin group. mNSS, modified Neurological Severity Score.

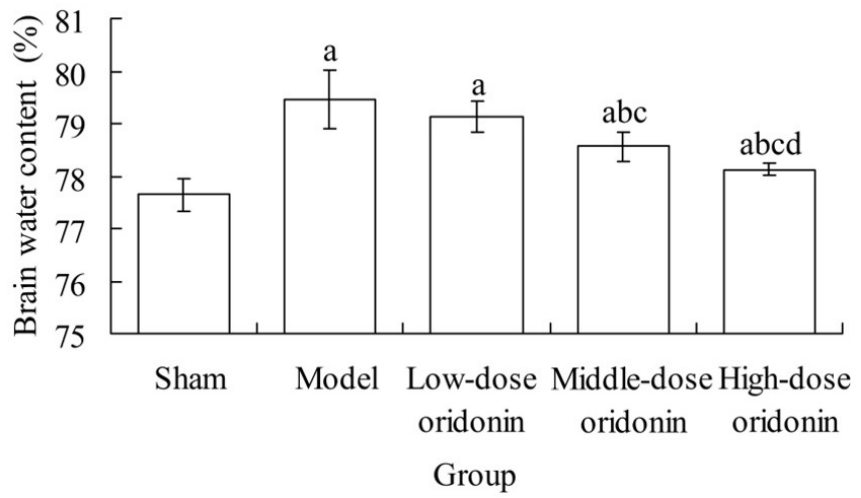

Figure 2. Comparison of $\mathrm{mNSS}$ among five groups ( $\mathrm{n}=6$ for each group; $\mathrm{F}=27.18086172 ; \mathrm{P}<0.001)$. ${ }^{\mathrm{a}} \mathrm{P}<0.05$ compared with sham group; ${ }^{\text {b }}<0.05$ compared with model group; ${ }^{\mathrm{C}} \mathrm{P}<0.05$ compared with low-dose oridonin group; ${ }^{\mathrm{d}} \mathrm{P}<0.05$ compared with middle-dose oridonin group

\subsection{Comparison of brain tissue TNF- $\alpha, I L-1 \beta$ and IL levels among five groups}

After $48 \mathrm{~h}$ from modeling, compared with sham group, in other four groups the brain tissue TNF- $\alpha$, IL- $1 \beta$ and IL levels were significantly increased, respectively $(\mathrm{P}<0.05)$. Compared with model group, the TNF- $\alpha$ level in low-dose, middle-dose and high-dose oridonin groups and the IL-1 $\beta$ and IL levels in middle-dose and high-dose oridonin groups were significantly decreased, respectively $(\mathrm{P}<0.05)$ (Table 1$)$.

\subsection{Comparison of brain tissue NF- $\kappa B$ p65, Nrf2 and HO-1 expression levels among five groups.}

The relative NF- $\kappa \mathrm{B}$ p65, Nrf2 and HO-1 expression levels in brain tissues in five groups were shown in Table 2. Compared with sham group, the NF- $\kappa B$ p65, Nrf2 and HO-1 expression level in model group were significantly increased, respectively $(\mathrm{P}<0.05)$. Compared with model group, the NF- $\mathrm{\kappa B}$ p65 level in middle-dose and high-dose oridonin groups was significantly decreased, respectively $(\mathrm{P}<0.05)$, and the Nrf2 level in middledose and high-dose oridonin groups and HO-1 level in low-dose, middle-dose and high-dose oridonin groups were significantly increased, respectively $(\mathrm{P}<0.05)$ (Table 2$)$.

\section{Discussion}

At present, there is no effective treatment for ICH in the elderly. The ICH-induced brain injury is caused by the occupation of hematoma itself and the destruction of hematoma surrounding tissue. It plays an important role in the prognosis of ICH patients (Nakamura et al., 2010). The brain edema and neurological dysfunction are the main manifestations of ICH-induced brain injury (Xiao et al., 2021). In this study, the oridonin with purity of $97.42 \%$ was extracted and purified from Rabdosia rubescens. Then, the rat model of $\mathrm{ICH}$-induced brain injury was established, and the protective effect of oridonin on ICH-induced brain injury was investigated. Results showed that, after treatment, compared with model group, the mNSS in middle-dose and high-dose oridonin groups was significantly decreased, and the brain water content was significantly decreased. This suggests that, the oridonin treatment can reduce the $\mathrm{ICH}$-induced brain injury in rats.

Microglia-mediated inflammatory injury plays an important

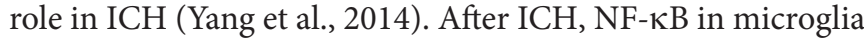
will be activated, which increases the release of pro-inflammatory factors and lead to early brain injury (Zeng et al., 2017). In addition, these pro-inflammatory factors, as the activators of NF- $\mathrm{KB}$, can promote the transcription of NF- $\mathrm{KB}$ with positive feedback and aggravate the inflammatory reaction. As an important nuclear transcription factor, NF- $\mathrm{KB}$ has been recognized as a key regulator of inflammatory reaction (An et al., 2002). Inhibition of NF- $\kappa B$ activity can reduce the neurological damage (Chen et al., 2018). In this study, after treatment, compared to model group, the brain tissue TNF- $\alpha$, IL-1 $\beta$, IL- 6 and NF- $\kappa B$ p 65 protein levels in middle-dose and high-dose oridonin groups were significantly decreased. We can identify that, the oridonin treatment can inhibit NF- $\kappa \mathrm{B}$ inflammatory pathway, thus mitigating the ICHinduced brain injury in rats. 
Table 1. Comparison of brain tissue TNF- $\alpha$, IL-1 $\beta$ and IL levels among five groups.

\begin{tabular}{lcccc}
\hline \multicolumn{1}{c}{ Group } & $\mathrm{n}$ & TNF- $\alpha$ & IL- $1 \beta$ & IL-6 \\
\hline Sham & 9 & $88.83 \pm 16.90$ & $36.52 \pm 6.29$ & $28.36 \pm 4.05$ \\
Model & 5 & $256.12 \pm 33.10^{\mathrm{a}}$ & $97.72 \pm 15.68^{\mathrm{a}}$ & $101.25 \pm 21.39^{\mathrm{a}}$ \\
Low-dose oridonin & 6 & $217.30 \pm 18.26^{\mathrm{ab}}$ & $85.24 \pm 13.28^{\mathrm{a}}$ & $84.17 \pm 19.27^{\mathrm{a}}$ \\
Middle-dose oridonin & 8 & $178.41 \pm 27.41^{\mathrm{abc}}$ & $73.88 \pm 15.17^{\mathrm{ab}}$ & $71.03 \pm 15.98^{\mathrm{ab}}$ \\
High-dose oridonin & 8 & $145.18 \pm 25.73^{\mathrm{abcd}}$ & $62.39 \pm 9.27^{\mathrm{abc}}$ & $52.24 \pm 7.04^{\mathrm{abcd}}$ \\
F & & 48.765 & 27.554 & 28.955 \\
P & & $<0.001$ & $<0.001$ & $<0.001$ \\
\hline
\end{tabular}

Sham group: $\mathrm{n}=9$; model group: $\mathrm{n}=5$; low-dose oridonin group: $\mathrm{n}=6$; middle-dose oridonin group: $\mathrm{n}=8$; high-dose oridonin group: $\mathrm{n}=8$. ${ }^{\mathrm{P}}<0.05$ compared with sham group; ${ }^{b} \mathrm{P}<0.05$ compared with model group; ${ }^{c} \mathrm{P}<0.05$ compared with low-dose oridonin group; $\mathrm{d} P<0.05$ compared with middle-dose oridonin group. TNF- $\alpha$, tumor necrosis factor $\alpha$; IL-1 $\beta$, interleukin $1 \beta$; IL-6, interleukin 6.

Table 2. Comparison of brain tissue NF- $\mathrm{BB}$ p65, Nrf2 and HO-1 expression levels among five groups.

\begin{tabular}{lcccc}
\hline \multicolumn{1}{c}{ Group } & $\mathrm{n}$ & NF-KB p65 & Nrf2 & HO-1 \\
\hline Sham & 9 & $0.67 \pm 0.04$ & $0.78 \pm 0.10$ & $0.42 \pm 0.06$ \\
Model & 5 & $1.01 \pm 0.03^{\mathrm{a}}$ & $1.16 \pm 0.07^{\mathrm{a}}$ & $0.67 \pm 0.08^{\mathrm{a}}$ \\
Low-dose oridonin & 6 & $0.98 \pm 0.05^{\mathrm{a}}$ & $1.19 \pm 0.08^{\mathrm{a}}$ & $0.89 \pm 0.11^{\mathrm{ab}}$ \\
Middle-dose oridonin & 8 & $0.77 \pm 0.04^{\mathrm{abc}}$ & $1.33 \pm 0.11^{\mathrm{abc}}$ & $1.05 \pm 0.09^{\mathrm{abc}}$ \\
High-dose oridonin & 8 & $0.72 \pm 0.06^{\mathrm{abcd}}$ & $1.42 \pm 0.12^{\mathrm{abc}}$ & $1.24 \pm 0.14^{\mathrm{abcd}}$ \\
F & & 74.203 & 50.735 & 84.615 \\
P & & $<0.001$ & $<0.001$ & $<0.001$ \\
\hline
\end{tabular}

Sham group: $\mathrm{n}=9$; model group: $\mathrm{n}=5$; low-dose oridonin group: $\mathrm{n}=6$; middle-dose oridonin group: $\mathrm{n}=8$; high-dose oridonin group: $\mathrm{n}=8$. ${ }^{\mathrm{a} P}<0.05$ compared with sham group; ${ }^{\mathrm{b}} \mathrm{P}<0.05$ compared with model group; ${ }^{\mathrm{P}}<0.05$ compared with low-dose oridonin group; ${ }^{\mathrm{P}}<0.05$ compared with middle-dose oridonin group. NF- $\kappa \mathrm{B}$, nuclear factor-kappa $\mathrm{B} ; \mathrm{Nrf} 2$, nuclear factor erythroid 2-related factor 2; HO-1, heme oxygenase 1.

Oxidative stress is an important cause of ICH-induced brain injury (Wang et al., 2018). Nrf2 is a key transcription factor and major regulator in oxidative stress. Its level gradually increases after ICH. Nrf2 can induce the expression of antioxidant genes and plays an important role in protecting brain tissue from oxidative damage after ICH (Wang et al., 2007). Study has shown that oridonin can promote the dissociation of keap-1 and Nrf2 by inhibiting NADPH oxidase. The dissociated Nrf2 enters the nucleus to activate the downstream protein $\mathrm{HO}-1$, which plays an antioxidant role in diseases (Yang et al., 2020). In our study, after treatment, compared to model group, the brain tissue Nrf2 and HO-1 protein levels in middle-dose and high-dose oridonin groups were significantly increased. This is similar to the results of above study, suggesting that oridonin may mitigate the ICH-induced brain injury in rats by promoting the antioxidant effect of $\mathrm{Nrf} 2 / \mathrm{HO}-1$ pathway.

\section{Conclusion}

In conclusion, oridonin from Rabdosia rubescens can mitigate the ICH-induced brain injury in rats. The mechanism may be related to its reduction of inflammatory response and oxidative stress by inhibiting NF- $\kappa B$ inflammatory pathway and promoting $\mathrm{Nrf2/HO}-1$ antioxidant pathway in brain tissues.

\section{References}

An, S. J., Pae, H. O., Oh, G. S., Choi, B. M., Jeong, S., Jang, S. I., Oh, H., Kwon, T. O., Song, C. E., \& Chung, H. T. (2002). Inhibition of TNF-alpha, IL-1beta, and IL-6 productions and NF-kappa B activation in lipopolysaccharide-activated RAW 264.7 macrophages by catalposide, an iridoid glycoside isolated from Catalpa ovata G. Don (Bignoniaceae). International Immunopharmacology, 2(8), 1173-1181. http://dx.doi.org/10.1016/S1567-5769(02)00085-1. PMid:12349954.

Belur, P. K., Chang, J. J., He, S., Emanuel, B. A., \& Mack, W. J. (2013). Emerging experimental therapies for intracerebral hemorrhage: targeting mechanisms of secondary brain injury. Neurosurgical Focus, 34(5), E9. http://dx.doi.org/10.3171/2013.2.FOCUS1317. PMid:23634928.

Chen, J., Yang, C., Xu, X., Yang, Y., \& Xu, B. (2018). The effect of focal cerebral ischemia-reperfusion injury on TLR 4 and NF- $\mathrm{BB}$ signaling pathway. Experimental and Therapeutic Medicine, 15(1), 897-903. PMid:29399096.

Holste, K., Xia, F., Garton, H. J. L., Wan, S., Hua, Y., Keep, R. F., \& Xi, G. (2021). The role of complement in brain injury following intracerebral hemorrhage: A review. Experimental Neurology, 340, 113654. http:// dx.doi.org/10.1016/j.expneurol.2021.113654. PMid:33617886.

Hong, Y., Liu, Q., Peng, M., Bai, M., Li, J., Sun, R., Guo, H., Xu, P., Xie, Y., Li, Y., Liu, L., Du, J., Liu, X., Yang, B., \& Xu, G. (2020). Highfrequency repetitive transcranial magnetic stimulation improves functional recovery by inhibiting neurotoxic polarization of astrocytes in ischemic rats. Journal of Neuroinflammation, 17(1), 150. http:// dx.doi.org/10.1186/s12974-020-01747-y. PMid:32375835.

Li, D., Han, T., Xu, S., Zhou, T., Tian, K., Hu, X., Cheng, K., Li, Z., Hua, H., \& Xu, J. (2016). Antitumor and antibacterial derivatives of oridonin: a main composition of Dong-Ling-Cao. Molecules (Basel, Switzerland), 21(5), 575. http://dx.doi.org/10.3390/molecules21050575. PMid:27144553.

Nakamura, T., Kuroda, Y., Hosomi, N., Okabe, N., Kawai, N., Tamiya, T., Xi, G., Keep, R. F., \& Itano, T. (2010). Serine protease inhibitor attenuates intracerebral hemorrhage-induced brain injury and edema 
formation in rat. Acta Neurochirurgica. Supplementum, 106, 307-310. http://dx.doi.org/10.1007/978-3-211-98811-4_57.PMid:19812969.

Rindler, R. S., Allen, J. W., Barrow, J. W., Pradilla, G., \& Barrow, D. L. (2020). Neuroimaging of Intracerebral Hemorrhage. Neurosurgery, 86(5), E414-E423. http://dx.doi.org/10.1093/neuros/nyaa029. PMid:32109294.

Sartippour, M. R., Seeram, N. P., Heber, D., Hardy, M., Norris, A., Lu, Q., Zhang, L., Lu, M., Rao, J. Y., \& Brooks, M. N. (2005). Rabdosia rubescens inhibits breast cancer growth and angiogenesis. International Journal of Oncology, 26(1), 121-127. http://dx.doi.org/10.3892/ ijo.26.1.121. PMid:15586232.

Sugiyama, T., Imai, T., Nakamura, S., Yamauchi, K., Sawada, S., Shimazawa, M., \& Hara, H. (2018). A novel Nrf2 activator, RS9, attenuates secondary brain injury after intracerebral hemorrhage in sub-acute phase. Brain Research, 1701, 137-145. http://dx.doi. org/10.1016/j.brainres.2018.08.021. PMid:30142309.

Thiex, R., \& Tsirka, S. E. (2007). Brain edema after intracerebral hemorrhage: mechanisms, treatment options, management strategies, and operative indications. Neurosurgical Focus, 22(5), E6. http:// dx.doi.org/10.3171/foc.2007.22.5.7. PMid:17613237.

Wang, J., Fields, J., Zhao, C., Langer, J., Thimmulappa, R. K., Kensler, T. W., Yamamoto, M., Biswal, S., \& Doré, S. (2007). Role of Nrf2 in protection against intracerebral hemorrhage injury in mice. Free Radical Biology \& Medicine, 43(3), 408-414. http://dx.doi. org/10.1016/j.freeradbiomed.2007.04.020. PMid:17602956.

Wang, S., Li, D., Huang, C., Wan, Y., Wang, J., Zan, X., \& Yang, B. (2018). Overexpression of adiponectin alleviates intracerebral hemorrhageinduced brain injury in rats via suppression of oxidative stress. Neuroscience Letters, 681, 110-116. http://dx.doi.org/10.1016/j. neulet.2018.05.050. PMid:29870775.

Wasserman, J. K., Zhu, X., \& Schlichter, L. C. (2007). Evolution of the inflammatory response in the brain following intracerebral hemorrhage and effects of delayed minocycline treatment. Brain Research, 1180, 140-154. http://dx.doi.org/10.1016/j.brainres.2007.08.058. PMid:17919462.

Wei, C. C., Kong, Y. Y., Li, G. Q., Guan, Y. F., Wang, P., \& Miao, C. Y. (2017). Nicotinamide mononucleotide attenuates brain injury after intracerebral hemorrhage by activating $\mathrm{Nrf} 2 / \mathrm{HO}-1$ signaling pathway. Scientific Reports, 7(1), 717. http://dx.doi.org/10.1038/ s41598-017-00851-z. PMid:28386082.

Xiao, A., Zhang, Y., Ren, Y., Chen, R., Li, T., You, C., \& Gan, X. (2021). GDF11 alleviates secondary brain injury after intracerebral hemorrhage via attenuating mitochondrial dynamic abnormality and dysfunction. Scientific Reports, 11(1), 3974. http://dx.doi.org/10.1038/s41598021-83545-x. PMid:33597668.

Xu, Y., Xue, Y., Wang, Y., Feng, D., Lin, S., \& Xu, L. (2009). Multiplemodulation effects of Oridonin on the production of proinflammatory cytokines and neurotrophic factors in LPS-activated microglia. International Immunopharmacology, 9(3), 360-365. http://dx.doi. org/10.1016/j.intimp.2009.01.002. PMid:19185062.

Yang, H., Huang, J., Gao, Y., Wen, Z., Peng, L., \& Ci, X. (2020). Oridonin attenuates carrageenan-induced pleurisy via activation of the KEAP$1 / \mathrm{Nrf} 2$ pathway and inhibition of the TXNIP/NLRP3 and NF- $\kappa \mathrm{B}$ pathway in mice. Inflammopharmacology, 28(2), 513-523. http:// dx.doi.org/10.1007/s10787-019-00644-y. PMid:31552548.

Yang, Z., Yu, A., Liu, Y., Shen, H., Lin, C., Lin, L., Wang, S., \& Yuan, B. (2014). Regulatory T cells inhibit microglia activation and protect against inflammatory injury in intracerebral hemorrhage. International Immunopharmacology, 22(2), 522-525. http://dx.doi. org/10.1016/j.intimp.2014.06.037. PMid:25000335.

Zeng, J., Chen, Y., Ding, R., Feng, L., Fu, Z., Yang, S., Deng, X., Xie, Z., \& Zheng, S. (2017). Isoliquiritigenin alleviates early brain injury after experimental intracerebral hemorrhage via suppressing ROS- and/ or NF-KB-mediated NLRP3 inflammasome activation by promoting Nrf2 antioxidant pathway. Journal of Neuroinflammation, 14(1), 119. http://dx.doi.org/10.1186/s12974-017-0895-5. PMid:28610608.

Zhang, Y., Chen, Y., Wu, J., Manaenko, A., Yang, P., Tang, J., Fu, W., \& Zhang, J. H. (2015). Activation of dopamine D2 receptor suppresses neuroinflammation through $\alpha \mathrm{B}$-crystalline by inhibition of NF- $\kappa \mathrm{B}$ nuclear translocation in experimental ICH mice model. Stroke, 46(9), 2637-2646. http://dx.doi.org/10.1161/ STROKEAHA.115.009792. PMid:26251254.

Zheng, X. C., Wu, Q. J., Song, Z. H., Zhang, H., Zhang, J. F., Zhang, L. L., Zhang, T. Y., Wang, C., \& Wang, T. (2016). Effects of Oridonin on growth performance and oxidative stress in broilers challenged with lipopolysaccharide. Poultry Science, 95(10), 2281-2289. http:// dx.doi.org/10.3382/ps/pew161. PMid:27143760. 